\title{
Erratum to: Jet physics in electron-proton scattering
}

\section{Thomas Schörner-Sadenius ${ }^{\mathrm{a}}$}

Deutsches Elektronen-Synchrotron (DESY), Notkestr. 85, 22607 Hamburg, Germany

Received: 1 August 2012 / Published online: 28 August 2012

(C) Springer-Verlag / Società Italiana di Fisica 2012

Erratum to: Eur. Phys. J. C (2012) 72:2060

DOI 10.1140/epjc/s10052-012-2060-8

The original version of this article unfortunately contained a mistake. Figure 31 was published as Fig. 30 due to a typesetting error.

The correct version of Fig. 30 is given below.

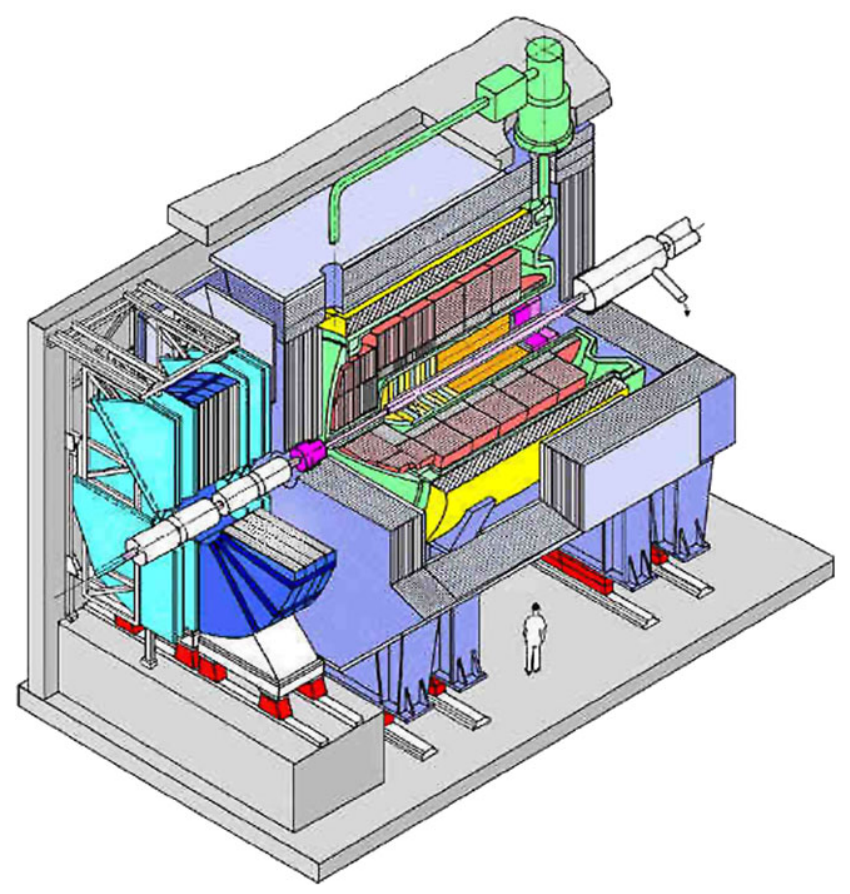

Fig. 30 The H1 detector at HERA. Source: H1

The online version of the original article can be found under doi:10.1140/epjc/s10052-012-2060-8.

a e-mail: thomas.schoerner@desy.de 